\title{
Making Connections to Re-engage Young People in Learning: Dimensions of practice
}

\author{
ANDREW CHODKIEWICZ, JACQUIE WIDIN \& KEIKO YASUKAWA
}

\begin{abstract}
In the field of literacy and numeracy education, a social practices approach has gained prominence among researchers who are sympathetic to the socio-cultural concepts of multiple literacies and numeracies in different social contexts. This article examines a case study of teaching literacy and numeracy to socially excluded young people in an Australian inner city youth centre. In their research, the authors critically challenged their taken for granted assumptions about what a pedagogy informed by a social practices approach to literacy and numeracy should look like. In understanding the apparent contradictions between what the authors had expected to see and what they were seeing, Kemmis's framework for the study of practice, based on the notion of practices as reflexive and dialectical, proved fruitful. The framework allowed the authors to interpret both the theory (the social practices approach to literacy and numeracy) and the practices at the youth centre in ways that deepened their appreciation of the theory - practice relationship.
\end{abstract}

\section{Introduction}

It's fun ...you get to be yourself... yeah.

They're not like other teachers, they'll sit down with you and explain it all...you know what you are doing.

One, you get a lot of help, two, you actually get work done and three, there's no pressure...it's relaxed and laid back.

These quotes are from some key actors in this story about a group of young people, their teachers, youth workers and volunteer tutors. The story is about how the young people, previously disengaged from education, successfully reconnect to school learning. Often work in this field is described as an arena of failure, and educators have great difficulty attracting and retaining learners (Long and Curtain 2006, McNeil and Dixon 2005, Aylward 2008). The young people at the centre of our research, and others in similar contexts, are often considered to be 'at risk'. For us, this term is problematic. It carries values and attitudes that construct the learners in negative ways. This article presents an alternative story of the way one group of so-called 'at risk' learners engage with learning, and it uncovers the elements that build and 
sustain a program to successfully meet the needs and concerns of the learners and the teachers who work with them.

A significant feature in this story is that this group of learners occupy an unnamed space between school and adult-focused education. The learners, as we show below, could not inhabit anything that resembled a school-type space, however, they are not yet self-directed adult learners. This presents pedagogical challenges for teachers in both school and adult education settings, as well as struggles for institutions like TAFE (Technical and Further Education) colleges. If these programs exist they are not given guaranteed ongoing funding and are most often located in the Outreach sections of TAFE.

This particular story is part of a larger study that investigated effective adult literacy and numeracy teaching. We drew on a longstanding partnership between an adult literacy and numeracy professional organisation (ALNPO) and an Australian university (Metro University - a pseudonym) in which we work, to research and document literacy and numeracy teaching in four different sites. In this article we focus on one site comprising an educational partnership between two sections of a TAFE college (partnership leader), a community youth service, and volunteers from the local community, including a local benefactor. In particular, we explore the educational program of two experienced teachers, Jean a literacy and numeracy teacher, and Peter a community outreach teacher, who work with young people attending a youth centre in an inner city suburb of Sydney.

Broadly speaking, we adopted a critical case study approach that engaged with the language, literacy and numeracy (LLN) field and provided insights into the learning and change dimensions of the practices described and investigated in this paper. The case study approach by its very nature is partial, particularistic and explanatory of the specific practices in the youth centre described here, however our analysis does lend itself to LLN programs in other contexts. Our analysis draws on multiple sources of data: interviews with teachers, learners, volunteers and youth centre staff; researcher observations; and video footage. The advantages of collecting data from multiple sources are many in this particular field of teaching practice; we were able to give voice to multiple points of view and were open to differing interpretations of events. The case study approach to research is often concerned with effecting change in the particular field of inquiry, (Yin 2008, Merriam 1998) and in this sense the results of the study may be used for professional development and in other related ways for practitioners in the field.

Jean's and Peter's educational program (within the TAFE and community centre partnership) was selected as a site of study for the project as a result of consultation with leaders of ALNPO and other experienced teachers in the field. The aim of the project was to capture some of the salient 
features of effective literacy and numeracy teaching practices that could be shared in the practitioner community, support new teachers, and inform policy.

The teachers, Jean and Peter are well known in the general LLN field and specifically for their work in the youth centre. They are both highly experienced and are advocates for LLN services through their professional organisations. As part of our research, we were invited to observe and document the teaching and learning in their program over a 20 week semester. We visited the youth centre on a regular basis during the 20 week semester (every second week) and held long discussions with the teachers (four meetings), youth workers (two meetings) and volunteer tutors (one meeting each) in the form of semi-structured interviews; observed six of the classes; and videotaped one day of classes. The educational partnership program was part of our broader teacher training work; Jean and Peter accepted a student teacher each and as university teacher educators we were involved with supervision visits and feedback meetings. We also took groups of student teachers for one-off observations over a much longer period (four groups during a 12 month period). We had a longstanding collegial relationship with Jean and Peter, and this created the opportunity for a joint approach to determining when and how data collection could be most fruitfully conducted. In many senses, we were participant observers; we had an established role in the scene under study and were insiders in the field who shared the concerns of the teachers we observed and interviewed (Atkinson and Hammersley 2007).

As researchers and teacher educators, an additional interest in exploring this program was to gain insights into the complexities of working in community-based educational programs and to explore teacher and learner practices in the broadest possible sense. In our view, the broad dynamics and relationships in the LLN field shape the teaching and learning practices. The questions below emerged both from our own understandings of social practices theory and critical literacy education, and our involvement with the program:

What are the processes by which the participants engage in the program?

What sustains and motivates the teachers to work in this context?

What are the 'teaching practices' and core beliefs that enable the teachers and volunteers to maintain the confidence that they are not going to fail?

How are the multiple relationships established and maintained in this particular context? 
We set out to examine teaching and learning practices in this unnamed space between school and adult education. We initially draw on what we knew: contemporary social practice theories and approaches to adult literacy and numeracy teaching. However as we discuss in detail below, approaches based on the learners' social context were not used to the extent or in the way we expected; as researchers we had to rethink the relevance and role of these approaches and thereby gained deeper understandings of teaching in this context.

\section{Finding a framework for the research}

In the field of literacy and numeracy education in the United Kingdom and Australia, a socio-cultural theory of literacy and numeracy (Street 1995, Baynham 1995, Baker 1998, Barton et al.2006, Papen 2005) has gained currency as a useful point of departure for studying adult literacy and numeracy practices in different contexts, and in turn for informing adult literacy and numeracy teaching and learning practices. It is tempting to simply 'look for' evidence of pedagogical approaches that the social practices view suggest (Appleby and Barton 2008). Indeed we did do so, however, initially we found some unexpected and disturbing contradictions or deviations from the theory that led us to examine and analyse the theory and our data more closely.

An approach to the study of practice as discussed by Kemmis (2005, forthcoming 2010) is helpful in understanding the apparent contradictions that could emerge in researching practice when one frames a study with a particular theoretical stance about what practice should 'look like' in the field. In particular, Kemmis argues that we need to expect and study practice as 'reflexive'; that is, that the practice of teaching is mutually constituted by tensions between the objective and subjective accounts of what makes a practice effective or professional. Using Kemmis' (forthcoming 2010) analytical framework for studying practice, in the context of teaching practice, a teacher's practice may be described 'objectively' by an outsider or someone who is expecting certain normalised behaviour to be followed, and also 'subjectively' by the teacher who would have their own beliefs and moral stance about what makes teaching meaningful to them. Furthermore, both of these accounts have to be interpreted within the wider social and political contexts in which the practice is taking place, and by which the teaching practice is both being shaped, and which the practice is shaping. These tensions in any teaching practice are also dynamic because there are different types of strategies employed by the teacher, learners, the teaching institution, and other near and distant stakeholders to exercise agency; not all of the stakeholders can exercise agency to resolve all of these tensions. However, rather than being puzzled by or ignoring the changes that are required and occur in practice as 'exceptions' to some established set of rules about what 
the practice should be, Kemmis suggests that experienced, 'knowing' practitioners 'search for saliences', that is, they 'search for knowledge in and through practice to correct and amend practice in light of changing circumstances and new perspectives' (2005: 421). For investigating teaching practice in an environment that is imbued with uncertainties - about funding, learner attendance, and learners' outside circumstances that could impact on their learning, the idea of 'searching for saliences' provides a useful lens.

Noddings (2003: 249) explains that teaching is fundamentally a relational practice between teachers and their learners that involves generating a safe environment and enthusiasm for learners to engage in a quest for new knowledge. In our analysis, we will focus on how the dynamics of this relationship is enacted by the teachers and the learners in the youth program. Using approaches to the study of teaching practice proposed by Kemmis (2005, 2007) and Noddings (2003) enable us to expose the political nature of teaching generally. We also reveal the particular politics around working with learners who are socially excluded from mainstream institutions and have a range of possibly negative expectations about re-engaging in learning (Long 2006, McNeil and Dixon 2005). In this paper we firstly describe the learners, their context, and their program. We then discuss the key insights into how the program engages and retains learners. We critically examine the multidimensional layers of the teaching and learning practices in the program, and interpret these observations drawing on, and at the same time critically reflecting on, a social practices approach to understanding literacy and numeracy.

\section{The learners}

The learners in our case study are a group of 12 young people, aged 15 to 18 years, half of whom are Aboriginal. These learners have dropped out of school before Year 10, and have not been linked into any further education, training or employment. Most have experienced difficulties with school-based learning, often as a result of significant gaps in their school literacies and numeracies. In addition to being excluded from formal learning and disconnected from school-type education, many of the young people have struggled with various behavioural issues such as anger and swearing, and have found it hard to concentrate. A number have minor physical difficulties that have never been addressed, such as being unable to read effectively because their eye-sight has never been tested. Others have ongoing alcohol and drug issues. Several are on juvenile justice orders, while there are some who have served time in juvenile detention.

They live in an inner city housing estate, where many young people are in precarious or chaotic home situations. They also have little financial security. The youth centre provides a safe and easily accessible space where 
they can meet, make friends and take part in a range of activities and programs that are supported by a mix of paid and volunteer staff.

When asked about what they needed out of a learning program, the young people attending the centre said that among their main concerns, a primary one was how to 'get a piece of paper to help them move on with their lives'. One of the ways of addressing this concern was to develop a program that provided a way for them to work on the school subjects they had missed out on, to further develop their literacy and numeracy, and to start achieving some successful completions.

\section{The program}

The program began as a result of an approach by the youth centre to a local TAFE college. Two sections at the college - Outreach and Adult Basic Education (ABE) - became involved. With the involvement of workers at the youth centre and some of the young people, a program was designed that could be delivered at the centre. At the same time the program organisers reached out into the local community to bring in volunteers to work with the learners, other key local school education and community agencies, and to gain the financial support of a local benefactor.

Over its first three years the program ran three times a week, with a core time when both teachers were available to work with the learners. The volunteers from the local area are key participants in the program as they provide additional one-on-one support for the learners. By enrolling in the program the young people are able to work on Year 10 School Certificate or equivalent modules and subjects, take a TAFE Preparation for Work and Study course and be part of excursions in and around the city. A number of short courses have also been arranged to help develop other work-related skills or qualifications.

\section{The centre}

The youth centre is situated on a main street amongst cafes, restaurants, bookshops, music shops and a range of other shops and services. Upstairs, on the second level of the youth centre, is a 'classroom' space, an attic area that is particularly brightly painted with vivid animations and graffiti like images. This classroom space contains a number of tables and chairs arranged in groups, with whiteboards and literacy and numeracy resources.

Significantly for most of the young people the program is often the first time that they have worked in groups. The youth centre is a place where the learners feel comfortable, a separate but safe haven, where they are encouraged and able to learn at their own pace. The Outreach teacher, Peter sees the centre as a place where the learners are able to re-connect with teachers and school learning in different and positive ways and where they are able to achieve successes with formal learning, for the first time. 


\section{The program develops}

Our initial visits to the centre and the college where some of the classes are held, presented us with some of the 'regular' elements of the field, with some learners coming in late and some attending irregularly, with the learners' outside world breaking through and impacting on their learning. At one class a student lay on the floor of the computer room for part of the session and other students found it difficult to concentrate. At another session, some students left during the break not to return and we found out the next day that the students had been arrested at the local shopping centre.

The teachers, working as a team, maintain connections with the students through all of these seemingly disruptive elements. The teachers are committed to providing educational opportunities for the learners and to enabling learners to achieve some success at each session. For Outreach teacher Peter it means:

If we sense that they feel that they are failing on the day, then we redesign what we are doing, so that they can always leave here [feeling] wow, I had a day there and I did well.

At times the behaviours they experience from some young people severely test their ability to keep the learners connected with the program. But the teachers still find ways to reconnect with the learners and keep them engaged:

There are times I know that when a student is angry ... we have little cues. We have that sense of when to jump in and when to get out... It's being able to navigate around all of these students and around their issues that come in with them (Peter, Outreach teacher).

We see that the teachers' practices embody the role of helping the learners achieve success by creating an environment of trust and safety. The learners describe their learning in the centre as 'fun', that the teachers are there to 'help' them through any difficulties with their particular studies, and that the teachers complement each other and work together. They feel strongly supported in their learning. Both teachers comment a number of times on this aspect of working in the program. They work well together, seamlessly negotiating a 'division of labour' with the students and keeping in constant contact with each other:

I suppose that's how we work ... there's a lot of communication that goes on outside of the room in between the breaks... during class and after class (Jean, ABE teacher).

The teachers demonstrate how knowing one's learners takes on a special dimension and how the context and particularities of the learners are 
paramount to the success of the program. Below we discuss what we have learned from observing the teachers and learners and how we have developed a new understanding of the notion of literacy and numeracy as social practices.

\section{Key insights}

\section{A nuanced understanding of the social practices approach to literacy and numeracy teaching}

The key tenets of a social practices approach to literacy and numeracy, drawing from the work of Barton et al. (2006), Papen (2005) and others, are that the approach:

- recognises people's literacy practices are shaped by their personal histories as well as the wider social and cultural environment in which they live, and this explains how particular practices have been learned and valued by individual learners;

- sees the personal histories and lives of individuals as rich sources of learning, and it provides both a validation of what the individuals know and a connection between literacy and numeracy and their life experiences.

In the youth centre, the learners live complex lives in which different forms of literacy and numeracy are practised. While there are gaps in their academic literacy and numeracy, they are not 'empty vessels' that wait to be filled with literacy and numeracy skills and knowledge. However, the teachers do not constantly refer to the learners' everyday experiences as a starting point in the way many social practices-based literacy and numeracy pedagogies might suggest. What is more noticeable is a focused attention on the work outlined in the standardised distance learning materials. Does this mean that rich life experiences and prior knowledge and skills are not being given recognition and validity in this program? Close observations and interviews with the teachers suggest otherwise.

The teachers are closely aware of the lives of their learners: the chaos and uncertainty that surround meeting basic needs, such as housing and food, and the teachers say that for some learners these uncertainties present themselves on a day-to-day basis. Some might argue that as survivors of these challenging situations they would have very sophisticated 'street' literacy and numeracy skills and experiences from which the classroom literacy and numeracy teachers could draw. However, there is no sign that the teachers elicit the learners' out of school experiences in this program. But neither do the teachers make any value judgments about the learners' street literacy and numeracy. 
What is evident in the way the teachers work is the very strict observance of a 'contract' between learners and teachers. Within the boundaries of the youth centre, the teachers provide almost unlimited support for the learners to achieve the learners' stated goal of completing the school curriculum. Peter, the Outreach teacher, commented on how the students are able to go off and work independently in different areas of the centre but they are keenly aware that the teachers are close by to help at any time. Far from denying the learners' histories and cultures, the physical environment of the centre represents strong affirmation of the learners' cultures. There is acknowledgement by the teachers and the centre staff and volunteers of the undeniable economic, social and educational disadvantages that these learners have faced in their lives through the historical tensions between Aboriginal and 'white' Australia. The teachers both acknowledge that they 'do need to be aware of the social world they are coming from because that's what is really impacting on their learning' (Peter, Outreach teacher). However, rather than focusing on the learners' disadvantages and their past, the teachers focus on the goals that the learners have identified for themselves: achieving the formal school credentials. The teachers work on creating an environment where they can shut out, as much as possible, the challenges of their students' 'everyday' lives, in order to create new possibilities. The learners said that at the youth centre, they felt supported and the teachers were there to help the learners achieve their stated goal(s). Peter (the Outreach teacher) was keenly aware of how the program needed to differentiate itself from formal schooling: 'I think one of the key ingredients for maintaining the program has been not to come with a model that has failed them before, such as a typical school model'.

A social practices approach to teaching literacy and numeracy often encourages the use of learners' personal histories to reveal how literacy and numeracy are socially and culturally contingent (Papen 2005, Appleby \& Barton 2008). For the young people in this program, their past and present lives were at times chaotic and unresolved in ways that took their focus away from their possible and positive foregrounds. It was not that the teachers encouraged the learners to abandon their community or deny the complexities of their lives. There was much in their lives that was beyond their current abilities to repair. The school certificate on the other hand was within their reach and for most of the learners provided a reason to remain involved and to access the support available in the youth centre. When a learner was disrupted or disengaged, both teachers played a key role in contacting them and re-engaging them with the program.

At a superficial level, the teaching in the youth centre may seem to be surprisingly functional and 'traditional' in its textbook-centred approach. An example is the use of print based distance-learning materials. We initially 
wondered where the authentic texts were that adult literacy and numeracy teachers have been taught to use? At a deeper level, however, this program enacts aspects of the fundamental rationale for a social practices approach. As Barton et al. (2006: 27) state, 'people use literacy to make changes in their lives; literacy changes people and people find themselves in the contemporary world of changing literacy practices'. The individuals who participate in the youth centre program are experiencing change, and in so doing are participating in the politics of literacy and numeracy. Their success in learning challenges any preconception that might have been held by themselves, their own community or people who prejudge the success of learners based on their backgrounds - be they social, cultural, economic, or educational. The education that the learners from this youth centre gain affords benefits to the learners individually and for their community. Their learning increases their human capital, that is the knowledge and skills that will enable them to increase the economic resources for them and their community. It also increases, arguably more importantly, their social capital, that is, both the networks and relationships between the young people themselves, and the new relationships between them and groups outside the community, such as with the TAFE college. These networks and relationships become resources to achieve shared goals (Schuller 2004, Balatti, Black and Falk 2007). These benefits are not achieved by accident or as a minor side-benefit, but rather as an intended consequence by virtue of the design of the program and the ways in which the teachers see their roles.

\section{Taking the 'risk' out of teaching and learning}

As mentioned earlier in this article, the notion of 'at risk' is at best problematic and its main role is discriminatory and negative in the way it demonises young people (Kelly 2007). There is an expectation that learners who have become excluded from formal schooling are difficult to teach and keep engaged in educational programs. There is, arguably, a high risk of 'failure' for the teachers in engaging with programs that require them to work with learners who can be easily distracted by the unpredictable events in their personal lives and who need induction into formal ways of learning. Indeed, there is a high risk of failure for all concerned: the learners, teachers and the partner organisations.

The teachers in the program are well aware of the fragile relationship between the students' participation and continuing attendance and the demands of daily life. The teachers' response to this situation is to operate from what they perceive as the needs of the learners. The teachers emphasise the importance of being empathetic to the learners literacy needs. Jean, the $\mathrm{ABE}$ teacher describes how the learners often have fundamental literacy needs and she is aware this makes them feel at a disadvantage: 
Some of the students come in with big needs in their literacy, some students have a lot of difficulty reading simple text...

they're a little bit ashamed about it too (Jean, ABE teacher).

Jean and Peter both talk about the possible interruptions the learners experience to their study and how they as teachers need to understand that the learners may take more time than usual to finish their course of study. Both teachers stress the need to support the students through this process rather than punish the students or make them feel as though they are not achieving their goals.

Anger presents a real risk to the learners' fragile relationship with this program. Some of the learners are often at risk of letting their anger determine how they participate on the day. The teachers are highly sensitised to the possibility of an explosive situation and respond in ways to diffuse the tension, picking up on clues and navigating around these situations.

In addition to the above strategies both teachers repeatedly refer to how the students need to be respected and to feel safe in their learning environment: 'They need to be able to feel trust, be respected and not to made fun of (Peter, Outreach teacher).

The way this project takes the risk out of learning is to provide a place where the learners feel welcomed, their goals can be realised and the teachers genuinely engage with them as people as well as learners. A key issue for us as 'interlopers' into this learning environment is the connectedness between and amongst the participants, teachers, youth workers and other interested people. The next section examines this more closely.

\section{Relational dimensions - connectedness across multiple layers and dimensions}

The connections are not only between the structures, the different centres and the key stakeholders, they are within the centre itself. We are struck by the subjective aspects of practice where the teachers embody the multilayered elements of the field and facilitate relations with and between the students, the volunteers and future educational partners. The teachers' ability to establish these strong and meaningful relationships demonstrates how connectedness is a key feature of teaching practice. The teachers' practices reflect Noddings's (2003) description of teaching as being a relational practice with a moral core.

The idea of teaching as a relational practice is illustrated by an event the teachers organised to celebrate the participants' achievements at the end of a teaching term. The learners' families and friends attended this event and the teachers recounted the positive impact that the celebration had on the learners and their respective guests and the wider community. Most had 
never experienced or been recognised for any positive learning outcome and the event acknowledged the participants as successful learners.

Another example of connectedness related by Peter (Outreach teacher) is his willingness to maintain the relationships that are established during the youth centre program. A group of learners had finished the school certificate program and wanted a vocational qualification (RSA - a short hospitality certificate), but they were not confident to undertake the certificate in the formal educational setting. Peter offered to do the short course with the group; he did this to encourage the young people and act as an 'anchor' for them in the course, but he too was learning the particular skills and so in all respects he believes they felt that he was genuinely participating in the course.

In a program such as this one it is important to recognise the different dimensions and layers of relationships that are established in order to get the program off the ground and to sustain it. Initially, there was the connection that the college had with the community in which the learners' lives were located. One of the teachers, Peter, comes from a community Outreach unit of the college, the central function of which is to broker educational programs with community groups and organisations. The success of the Outreach unit relies on the teachers having real connections and knowledge of their local community, as well as a cooperative working arrangement with the ABE Unit in the college where the other teacher, Jean, works.

'Brokering' the type of partnerships on which this program is based is not straightforward. The program exists in an economic environment of reduced resources in public education institutions, where mainstream vocational and technical education is privileged over access and general education and where there may be complex local community politics that need to be sensitively considered. This program also relies heavily on being able to recruit suitable volunteers from the community. Here the cooperation of the community youth worker in being able to identify people who are willing to work with the learners on a one to one basis, and who have attributes that are likely to support them in their roles, is critical. This shows the importance of bringing together and maintaining the network of Outreach, ABE, youth centre, the learners' community, and the volunteers to support the program.

The teachers actively form relationships of trust and respect with the learners. This is evident in the way they talk to the learners as people who are expected and able to take responsibility for their own learning. But it is a relationship that also acknowledges the variable and perhaps negative experiences that the learners have had with education prior to engaging in this program. The teachers listen to what the learners want most of all out of this learning - to be able to accomplish the school modules that they could not engage with in the formal school environment. One of the key aspects of the relationships between the teachers and the learners is that learners can rely on 
the teachers to help with any aspect of their work, to know that the teachers are on hand to give assistance when they need it. The teachers and students maintain this connection as long as the learners stay within the boundaries of the youth centre.

Both teachers comment on the level of trust that needs to develop between the teachers and learners with regard to maintaining the boundaries. Jean describes how the learners need to leave the centre at times, for example, to go for a smoke, to visit a café, or just unwind. This is permitted and the teachers trust that the students will return; the learners also trust that the teacher will carry on from where they left off. The learners and teachers are developing their relationships beyond the usual teacher-student roles.

\section{A critical understanding of program flexibility}

Both teachers and learners in this program attribute some of the successes to the program's ability to be flexible. However, the flexibility in this program is many layered, and in some areas, qualified. The notion of flexibility is often associated with good adult learning principles, such as: teachers and learners negotiating the process of learning, adapting the teaching focus to the learner's individual goals and interests, and encouraging self-assessment rather than reliance on teacher assessment (Jarvis et al. 2004). These expressions of flexibility assume a high level of self-direction and ownership of learning by the learners.

These principles do not necessarily apply to this program. We have already discussed the reasons for not drawing directly on the learners' lives as a central component of their curricula, but rather, using a standardised set of learning resources with exercises that the learners work on with the assistance of the teachers and volunteers. Observing the learners work through the exercise sheet could easily invite criticisms of instrumental learning, arguably the very opposite to a social practices approach.

The idea of flexibility is not often tied to instrumental learning. However another benefit of allowing space for instrumental learning can be seen when we consider the nature of instrumental learning compared to more conceptual or relational learning. Skemp (1976 cited by Selinger 1994) explains that learning instrumentally or by rote, provided the 'rules' or procedures to follow are stated clearly, is easier and quicker than learning relationally. For learners who carry the stigma of 'failure', being able to present a page of completed exercises with correct answers is an important achievement. In our case study, we see the teacher, Peter, checking the folder of completed worksheets of one of the learners, and sending her off to complete the next module. This apparently routine relationship of teacher and learner in this exchange illustrates the significant trust that has formed between the teacher and learner. Here the learner is being expected and 
trusted to go away and do the work, and the teacher is being seen as someone who would acknowledge their achievements and who would have expectations of them as learners. These developments in the relationship between the teacher and learner are critical in taking the risk out of learning for the learners, and in turn the risk out of teaching for the teachers.

In addition to the individual work, we see the teachers bringing learners together in a group to play word game. The teachers say that it is a way of making the learning of words fun and connecting them through language to other parts of the real world.

[When] doing things like these word games, words come up that are a mystery to them, that they may have heard and are not quite sure of, so they get a curiosity about it and doing it in this game way makes it fun (Jean, ABE teacher).

Word games also enabled the teachers to extend the learners' literacy learning, for example, to work on spelling patterns and rules that emerge out of the games.

We do not argue that instrumental learning is therefore what should be promoted in a program such as this. However, its value in enabling students to gain successes and interest in learning must be acknowledged, particularly given their previous experiences of school as a place of failure and exclusion.

\section{Flexibility in Teaching}

A prominent theme in teaching in non-formal / informal contexts is the notion of 'being flexible' in one's approach to teaching (Brookfield 2006), and clearly this is a significant factor for the teachers working in this program. The teachers use this notion of flexibility to describe how they make decisions to continue or not continue with a particular teaching segment; working with particular students or changing how they relate interpersonally with students. Peter describes the complexity of this teaching context:

It is good the way we can switch into something very quickly... we might have 10 students doing 10 different things individually and we need the flexibility to be able to turn them onto a Imathsl question about sign or trig and then go back to the spelling or to move over to the project. So we move very quickly in terms of subject area. It's not stand at the front of the room and deliver a lesson (Peter, Outreach teacher).

These quick decisions that teachers make are in line with the notion of professional 'discretionary judgement' (Beckett 1996) that involves decisions contingent on relevant factors including the teachers' beliefs about the particular circumstances and the people present. In other words, the way teachers decide what they will do, continue with and so on, is dependent on what else is going on. The teachers draw from their practical and theoretical 
knowledge about teaching and from their deep understanding of the historical, social and material conditions which shape the situation they are currently working in. Kemmis (2005: 392) names this aspect of practice as searching for 'saliences', that is, the teachers drawing on their knowledge and life experience reflexively and responding to changing situations as they unfold. To call this flexibility does not fully acknowledge or describe the store of knowledge the teachers are drawing on to make the moment-to-moment decisions in this teaching environment.

\section{Conclusion}

The teaching and learning practices demonstrated in this program show how with skill, knowledge and a deep commitment to relational practice, a group of learners previously excluded from formal education reengage to achieve their learning goals.

Attempting to make sense of practices while assuming that practices should reflect theory and knowledge in a particular way is fraught with uncertainties and the uniqueness of learning events (Kinsella, 2007). It also ignores the transformation of teaching practices when the teachers interact with the particularities of the learners and their lives that may be different from one day to the next. Kemmis's idea of 'knowing practices' as 'searching for saliences' $(2007 ; 2005)$ enables us to see the dynamism of both teaching and learning practices in a critical way. The alternative is to understand teaching practices as something stable and predictable, that could then lead to positioning the uncertainties and unpredictability that learners bring to the class as disruptive forces. Coming with the expectation that a knowing practice' is about interacting with, sometimes resisting and sometimes responding to unanticipated events with thought, the hindsight of experience, theorised understanding as well as a deep appreciation of the 'here and now', enabled us as researchers and the teachers to interrogate constructs such as 'youths at risk'. An objective research based on some of the dominant discourses about 'youths at risk' might have focused on how teachers managed the learners who in many dominant discourses could be categorised as 'at risk' and difficult learners to work with. The connectedness of the learners to learning and connectedness to the 'real world' both played a role in focusing on both individual and contextual aspects.

While this study was qualitative and limited in its generalisability, it points to the value of seeing teaching practices more broadly. It is hoped that along with other practitioner led research it will contribute to further discussion and inquiry into teaching practices in community settings. 


\section{References}

Appleby, Y and Barton, D (2008) Responding to People's Lives, National Research and Development Centre for Language and Literacy, London.

Atkinson, P and Hammersley, M (2007) Ethnography: Principles in Practice, $3^{\text {rd }}$ edition, Routledge, New York.

Aylward, N (2008) Learning from the Edge, Adults Learning, vol 19, no 5, pp 24-25.

Barton, D, Appleby, Y, Hodge, R, Tusting, K, and Ivanic, R, (2006) Relating Adults' Lives and Learning: Participation and engagement in different settings National Research and Development Centre for Language and Literacy, London.

Baker, D (1998) Numeracy as Social Practice, Literacy and Numeracy Studies, vol 8, no 1, pp 37-50.

Balatti, J, Black, S, and Falk, I (2007) Teaching for social capital outcomes: The case of adult literacy and numeracy courses, Australian Journal of Adult Learning, vol 47, no 2, pp 245-63.

Baynham, M (1995) Literacy Practices: Investigating literacy in social context. Longman, London.

Beckett, D (1996) Critical judgment and professional practice, Educational Theory, vol 46, no 2, pp 135-149.

Brookfield, S (2006) The Skillful Teacher, Jossey-Bass, San Francisco.

Jarvis, P, Holford, J, and Griffin, C (2004) The Theory and Practice of Learning, Routledge - Falmer, London.

Kelly, P (2007) Governing individualised risk biographies: New class intellectuals and the problem of youth at-risk, British Journal of Sociology of Education, vol 28, no1, pp 39-53.

Kemmis, S (2005) Knowing Practice: Searching for saliences, Pedagogy, Culture and Society, vol 13, no 3, pp 391- 427.

Kemmis, S (forthcoming 2010), What is professional practice? In Kanes, C, (ed), Developing Professional Practice, Springer, Amsterdam.

Kinsella, EA (2007) Embodied reflection and the epistemology of reflective practice, Journal of Philosophy of Education, vol 41, no 3, pp 395409.

Long, M and Curtain, R (2005) How Young People are Faring, Dusseldorp Skills, Glebe, NSW

Merriam, SB (1998) Qualitative Research and Case Study Applications in Education, Jossey-Bass, San Francisco.

McNeil, B and Dixon, L (2005) Success Factors Informal Learning: Young adults' experiences of literacy, language and numeracy, National Research and Development Centre for Language and Literacy, London. 
Noddings, N (2003) Is Teaching a Practice? Journal of Philosophy of Education, vol 37, no 2, pp 245-251.

Papen, U (2005) Adult Literacy as Social Practice: More than skills. Routledge, London and New York.

Schuller, T (2004) Three Capitals: A framework, in Schuller, T, Preston, J, Hammond C, Brassett-Grundy, A and Bynner, J (eds), The Benefits of Learning: The impact of education on health, family life and social capital, Routledge-Falmer, London, pp 12-33.

Selinger, M (1994) Understanding, in Selinger, M, (ed), Teaching Mathematics, Routledge, London, pp. 185-194.

Street, BV (1995) Social Literacies : Critical approaches to literacy development, ethnography, and education, Longman, London

Yin, RK (2008) Case Study Research: Design and methods, Volume 5 of Applied Social Research Methods, Sage, New York. 